\title{
Photochemical investigation of aromatic hydrocarbons of Balakhani crude oil as petroleum luminophores
}

\author{
Ulviyya Yolchuyeva ${ }^{1} \cdot$ Rena Japharova $^{1} \cdot$ Amir Reza Vakhshouri $^{2} \cdot$ Matlab Khamiyev $^{1} \cdot$ Chimnaz Salmanova $^{1}$. \\ Gunay Khamiyeva ${ }^{1}$
}

Received: 27 May 2020 / Accepted: 11 August 2020 / Published online: 26 August 2020

(c) The Author(s) 2020

\begin{abstract}
In this paper, the photochemical conversion process of aromatic hydrocarbons in Balakhani oil well (BO) as a case study was investigated. To study the composition of $\mathrm{BO}$, first, it has been separated into the first, second, third, and fourth groups of aromatics using chromatography absorption column. It has been established that the composition of the separated groups is mainly composed of mono-, tri-, and tetracyclic aromatic hydrocarbons. It has been shown that the optical densities of the absorption bands corresponding to bi-, tri-, and polycyclic aromatic hydrocarbons decrease with increasing the photoirradiation period, hence their maximum absorption band undergoes the hypsochromatic shift, which is characteristic for electron donor substances. It has been determined that the photochemical conversion process in the sample oil (BO) occurs with radical-chain and molecular mechanisms. As a result of the photochemical conversion process of arene-type aromatic hydrocarbons, the first difference during the photooxidation of endoperoxides, hydroxynones, quinones, and phenes is the formation of cyclic peroxides and quinones.
\end{abstract}

Keywords Balakhani oil · Photo-irradiation process $\cdot$ Petroleum luminophores $\cdot$ UV spectroscopy $\cdot$ Photochemical conversion

\section{Introduction}

For the petrochemical and oil-refining industries to be permanently in the spotlight of countries with rich oil fields, it is required to develop fundamental and applied research in the field of studying the primary and secondary products of oil refining. Currently, these studies are carried out with the widespread use of novel high-sensitive, modern spectral analysis methods (UV-, IR-, NMR-, EPR- and chromatomass spectroscopy and luminescence) $[2,22,24]$ and thermal devices (DSC, DTA, etc.) $[8,17]$, which allows us to fully explain the processes of photophysical and photochemical transformations in the structural group of oil products

Matlab Khamiyev

mxamiyev@yahoo.com

Amir Reza Vakhshouri

amir.vakhshouri@bhos.edu.az

1 Institute of Petrochemical Processes, Azerbaijan National Academy of Sciences, 30, Khojaly Ave., 1025 Baku, Azerbaijan

2 Baku Higher Oil School, Khojaly Ave. 30, Baku, Azerbaijan as well as clarification of their kinetics, the elementary steps and their mechanisms.

It is known that oil consists mainly of aromatic, naphthenic-paraffin and olefin hydrocarbons [28]. However, despite the fact that the properties of each of these hydrocarbons and their role in various photophysical and photochemical processes have been studied for a long time [12], the role of complex oil systems, especially their features as one of the constituent components of primary oil products in the processes of photochemical transformation have not yet been studied. Thus, in petroleum, several photophysical and photochemical transformations can occur over time as a result of radiation as well as sunlight and the effect of molecular oxygen $[13,20]$.

Studying these processes is crucial for the efficient storage and usage of petroleum $[4,9,15]$. The photooxidation process is a significant process in the degradation of oil. Thus, during the photochemical process under the influence of sunlight, saturated hydrocarbons in oil are very stable while aromatic hydrocarbons are more sensitive [7].

Despite the presence of numerous aromatics, naphthenic and paraffin-based oil fields in the world, including the 
Republic of Azerbaijan, most of the research in this area is related to secondary oil-refining products $[15,16,18,19,23$, $25]$. Thus, photophysical and photochemical processes that occur under the influence of photo-irradiation in petroleum luminophores (PLs) resulting from catalytic cracking of heavy diesels [26] or pyrolysis of heavy tars [3] as secondary oil-refining products were studied, and the mechanisms of their occurrence has also been investigated.

It was found that photochemical processes in PLs follow two mechanisms: ion radical and molecular. In the ion-radical mechanism, radicals formed during the heating process (such as; $\mathrm{H \bullet}, \mathrm{R} \bullet, \mathrm{HO}_{2}^{\bullet}, \mathrm{RO}_{2}^{\bullet}$ etc.) in the presence of molecular oxygen participate in the processes of radical-ion recombination and form molecular products. The resulting compounds (tetraoxides, endoperoxides, etc.) are decomposed by a molecular mechanism during the heating process [1].

The above-mentioned PL substances have ability to accumulate sunlight as a photosensitizer in decomposition of some compounds such as alcohols and paraffins with ionization energies greater than $9 \mathrm{eV}$ and can also be used as photo-stabilizers of polymers. Additionally, PLs have high luminescence ability in the visible spectral region. Therefore, they are mainly used in the detection of nanoscale defects in colored-luminescent defectoscopy. However, these luminophores lose their photostability over time, which restricts their long-term application. In this regard, the development of a more photostable PLs is extremely imperative.

As a result of some studies, it has been found that the amount of aromatic hydrocarbons in primary oil-refining products is insignificant and also the condensation rate is low. They are environmentally sustainable and harmless due to their stability and on the other hand, they have valuable raw material sources. Therefore, solving the above problem using petroleum products has received much attention.

As stated before, crude oil is a complex mixture of organic compounds, hence it is difficult to characterize using optical methods because of its dark color. On the other hand, ultraviolet-visible (UV-vis) spectroscopy is a simple, a practical, and an inexpensive method. It allows the characterization of crude oil through dilution in solvents such as hexane. Therefore, for the first time, in this study, the aromatic components extracted from Balakhani crude oil (BO) were exposed to photo-irradiation at different period of times to be used as PLs. By exposure to photo-irradiation, the task is to fully study the processes of photochemical transformation, the elementary steps of these processes and their mechanisms with the help of modern and high-sensitivity devices.

\section{Research object and methodology}

As a research object, the Balakhani oil well (BO), located in the Absheron Peninsula of Azerbaijan and obtained at depths of 750-150 m, is known as low-paraffin oils, that contains high amount of mono- di-, and tri- cycloalkanes [30]. BO sample, based on refractive index, was first separated into hydrocarbon fractions (paraffin naphtha, first-, second-, third-, and fourth-group aromatics and tars) using column adsorption chromatography (LAC) with the following specifications; height and inner diameter of the column 250 and $5.5 \mathrm{~cm}$, respectively, which are filled with silica gel as the adsorbent.

This separation process was carried out according to the refractive index based on GOST 11244-76. It has been determined that BO sample is mainly composed of paraffin naphtha (66\% by weight), aromatics (37.13\%) and heavy fraction hydrocarbons - $\operatorname{tar}$ ( $8 \%$ by weight).

Similarly, based on the same method, the aromatic part divided into subgroups was identified and measured. All groups derived from the BO sample as well as some of their properties are summarized in Table 1.

The main purpose of this study is to investigate the photochemical transformation processes over different time periods and their mechanisms in the aromatic groups separated from the BO sample, at different times, using UV/Vis and IR spectroscopy. On the other hand, it is known that the absorption bands of hydrocarbons in the UV/Vis spectral range are slightly broad (e.g., acetone from 250 to $300 \mathrm{~nm}$ ).
Table 1 Some physical and chemical properties of $\mathrm{BO}$ and its hydrocarbon components

\begin{tabular}{llllll}
\hline Petroleum and its composition & $\begin{array}{l}\text { Molecular } \\
\text { weight }\end{array}$ & $\begin{array}{l}\text { Density, } \\
20^{\circ} \mathrm{C}(\mathrm{kg} / \\
\left.\mathrm{m}^{3}\right)\end{array}$ & $\begin{array}{l}\text { Viscosity, } \\
40^{\circ} \mathrm{C}\left(\mathrm{mm}^{2} / \mathrm{s}\right)\end{array}$ & $\begin{array}{l}\text { Refractive } \\
\text { index, } n_{\mathrm{d}}^{20}\end{array}$ & $\begin{array}{l}\text { Content in } \\
\text { petroleum } \\
(\%)\end{array}$ \\
\hline $\begin{array}{l}\text { Balakhani oil } \\
\begin{array}{l}\text { Paraffin } \\
\text { naphtha }\end{array}\end{array}$ & 284 & 887.8 & 17.8 & - & 100 \\
First-group aromatics & 229 & 855.1 & 18.5 & 1.4748 & 66 \\
Second-group aromatics & 333 & 905.1 & 32.1 & 1.5028 & 6 \\
Third-group aromatics & 525 & 946.4 & 33.2 & 1.5304 & 6.46 \\
Fourth-group aromatics & 545 & 982.7 & 35.4 & 1.5594 & 3.19 \\
Tar & 562 & 1000.7 & 39.7 & 1.5975 & 9.48 \\
\hline
\end{tabular}


Hence, amongst the analysis of a multi-component mixture, the absorption bands of different compounds can easily overlap which makes it more challenging than IR-absorption spectroscopy [5]. Like other petroleum products, the UV spectrum of $\mathrm{BO}$, which has multifarious hydrocarbon content, overlaps each other, making it difficult to accurately study its hydrocarbon content. For this reason, the aromatics derived from the $\mathrm{BO}$ sample, exactly like the above method (according to the GOST 11244-76 standard method) are separated into subgroups. In this process, solvents of hexane, benzene, hexane-benzene mixture (with a ratio of 1:1) and ethanol-benzene mixture (with a ratio of $1: 1$ ) were used.

To carry out the photooxidation process, dilute solutions of the samples in the hexane $(0.01 \mathrm{~g} / \mathrm{L})$ were prepared. Measuring devices are equipped with a high-precision optical system and sensor that enables simultaneous measurement of the sample and the reference to optimize measurement accuracy. The device's optical transmission is $0.1 \mathrm{~nm}$, and all data on measurements and optical spectra are performed by a computer. Mercury and incandescent lamps are used as a source of excitement. The amount of polycyclic aromatic hydrocarbons has been determined according to the appropriate method [27]. A PRK-4 mercury lamp and a UBS-5 filter were used to study the photochemical conversion processes in $\mathrm{BO}$ samples.

The electron absorption spectra of the samples were measured on a JENWAY - $6850 \mathrm{UV} / \mathrm{vis}$ Spectrophotometer, at a spectral range of 190-1000 nm, at room temperature using quartz cuvette $(d=1 \mathrm{~cm})$.

IR spectroscopy was performed on an IR-Alpha and LUMOS (Bruker) device at room temperature in the spectral range of $600-4000 \mathrm{~cm}^{-1}$.

\section{Results and discussion}

Various solutions with different concentrations of $\mathrm{BO}$ and its separated aromatic hydrocarbons in hexane as solvent were prepared and analyzed using UV-Vis spectroscopy (Fig. 1). Based on the obtained spectra, the amount of aromatics in dilute solutions is calculated and summarized in Table 2.

In addition to the polycyclic aromatic hydrocarbons given in Table 2, very small amounts of 1,2-benzanthracene, 3,4-benzphenanthrene and pyrene were also found in $\mathrm{BO}$ and its components. However, due to the difficulty of calculating their diminutive amount, they were ignored from the table.

As can be seen from Fig. 1, the absorption peaks at lower concentrations are clearly observed. Therefore, dilute sample solutions were used to study the photovoltaic effects at certain time intervals then their UV spectra were determined and shown in Fig. 2.

As can be seen, in the electronic absorption spectrum of the first-group aromatic components (at $0.0021 \mathrm{~g} / \mathrm{L}$ solution) without photo-irradiation, the absorption maxima at 226 and $253 \mathrm{~nm}$ corresponding to the naphthalene and phenanthrene, respectively, were observed. The maximum optical intensity of the absorbed band for the first-group aromatics increased from 1.7 (no irradiation) to 3.0 after 30 min of photo-irradiation. Irradiation of first-group aromatic hydrocarbons for 30 min leads to an increase in the intensity of the maximum of the absorption band in the region of 270-300 nm from 0.5 to 1.2 and also a new absorption band is formed at $253 \mathrm{~nm}$. This indicates that during the irradiation period, these groups of aromatics have undergone a photo-oxidation process (Fig. 2a).

Continuing the photo-irradiation process up to $60 \mathrm{~min}$ results in an increase in the intensity to 3.12 in the range of 200-250 nm. After $1 \mathrm{~h}$ photo-irradiation, the intensity of the newly formed maximum absorption band in $253 \mathrm{~nm}$ increases from 1.2 to 1.7 . After $3 \mathrm{~h}$ irradiation, the maximum absorption band $\left(\lambda_{\max }\right)$ of naphthalene hydrocarbon $(226 \mathrm{~nm})$ shifts in a hypsochromic manner to the short-wave region of the spectrum (up to $223 \mathrm{~nm}$ ). In addition, after this irradiation period, an increase in the intensity of the adsorption band related to benzene hydrocarbons was observed (3.7). Further increase in irradiation dose caused hypsochromic shift in the value of the $\lambda_{\max }$ from 253 to $251 \mathrm{~nm}$. This indicates the formation of endoperoxides as a result of photooxidation of the naphthalene and phenanthrene type aromatics in the composition of the first group [14]. Moreover, further increasing the radiation dose helps to limit the absorption bandwidth and the formation of hydrocarbons with fine structures.

In addition to the first-group aromatics, other groups of aromatics in BO were also subjected to different photo-irradiation processes and their structural changes were investigated by UV spectroscopy.

The optical intensity of the $\lambda_{\max }$ of naphthalene from the second-group aromatics at $224 \mathrm{~nm}$ decreased from 2.48 to 2.17 after $30 \mathrm{~min}$ of photo-irradiation, which is in contrast to the first-group aromatic composition. The new absorption band is observed at $251 \mathrm{~nm}$ (Fig. 2b). By increasing the irradiation time up to approximately $1 \mathrm{~h}, \lambda_{\max }$ of 224 and $251 \mathrm{~nm}$ are slightly shifted to the short-wave region of the spectrum in hypsochromic manner. Further increase in irradiation time results in formation of the absorption bands at 224 and $247 \mathrm{~nm}$. In this case, the optical intensity of the $\lambda_{\max }$ significantly increases from $0.5028(251 \mathrm{~nm})$ to 0.8613 $(247 \mathrm{~nm})$. In addition, the relative intensity of the main absorption bands changes after this irradiation period. As with the components of first and second aromatic groups in the third group, after $1 \mathrm{~h}$ irradiation, the optical densities of mono aromatics (204 nm) increased from 1.44 to 2.56 and bi aromatics $(227 \mathrm{~nm})$ decreased from 2.5 to 2.11 for benzene and naphthalene, respectively. In this case, the $\lambda_{\max }$ of the phenanthrene $(254 \mathrm{~nm})$ shifts in a hypsochromic manner

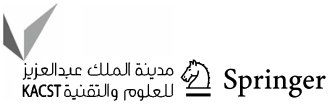




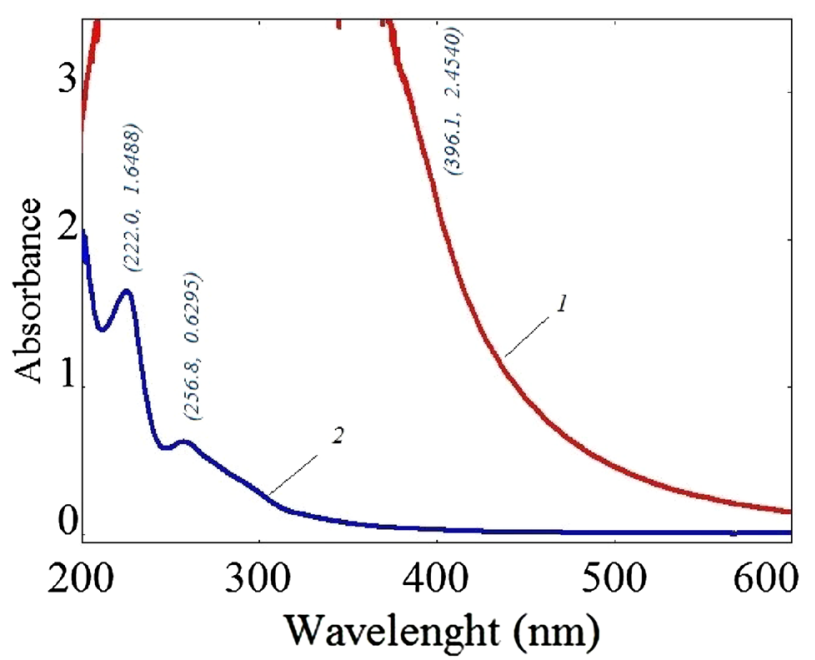

(a)

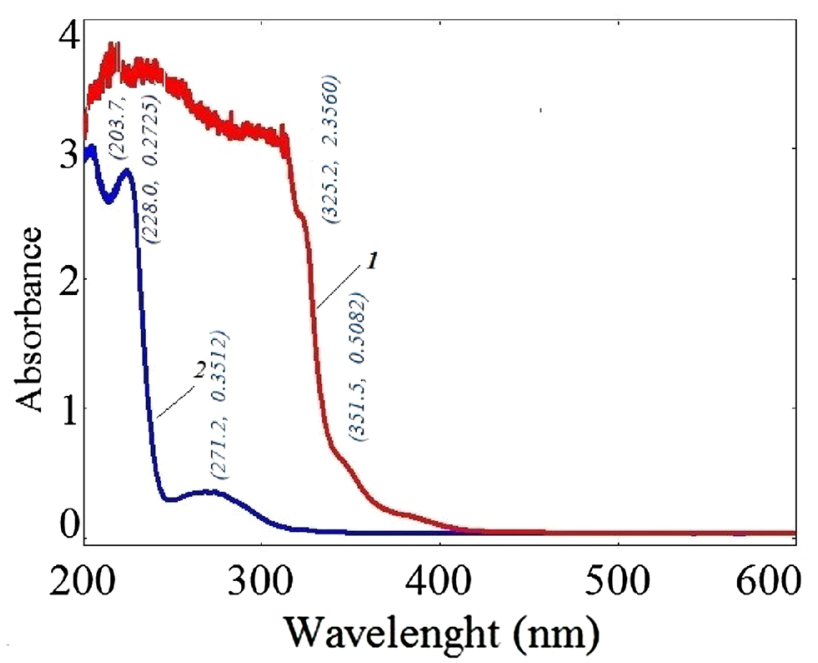

(c)

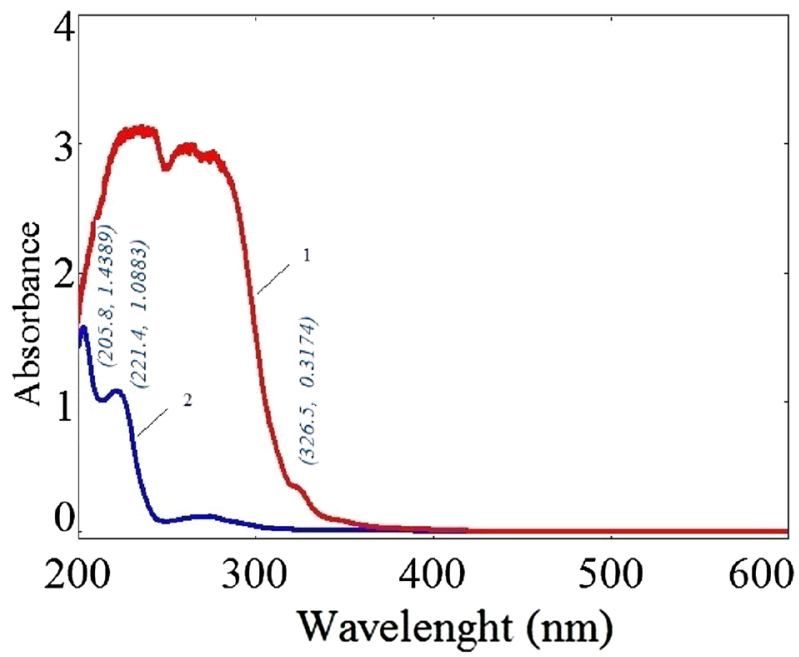

(b)

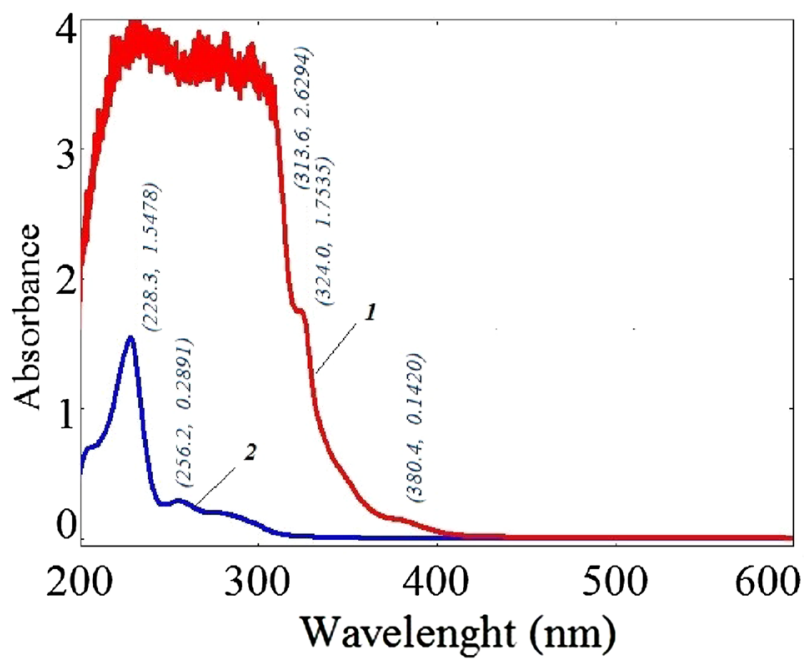

(d)

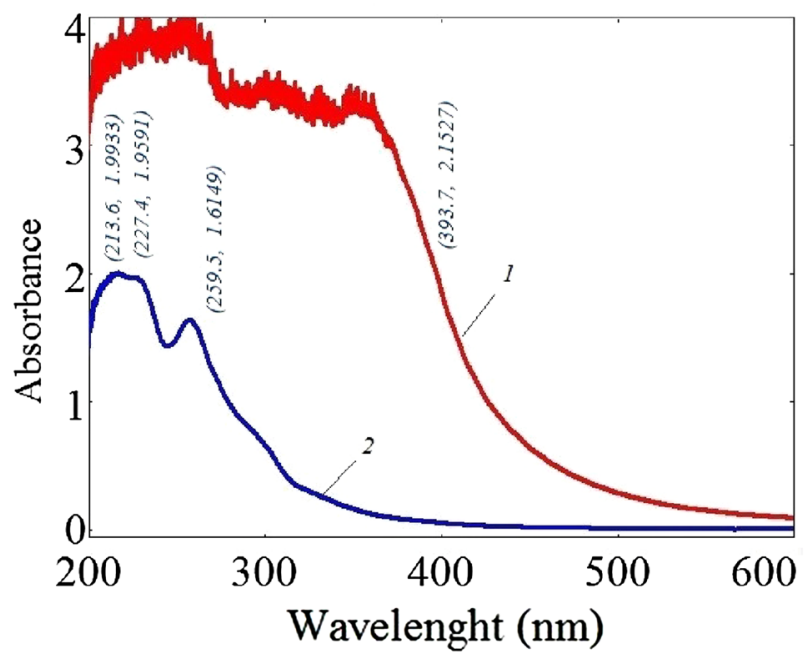

(e) 
4 Fig. 1 Electron absorption spectra of $\mathrm{BO}$ and its components in various concentrations. a BO sample (crude oil) (1) $C=0.02 \mathrm{~g} / \mathrm{L}$; (2) $0.001 \mathrm{~g} / \mathrm{L}, \quad$ b first-group aromatics, (1) $C=0.02 \mathrm{~g} / \mathrm{L}$; (2) $C=0.0021 \mathrm{~g} / \mathrm{L}$, c second-group aromatics, (1) $C=0.02 \mathrm{~g} / \mathrm{L}$, (2) $C=0.003 \mathrm{~g} / \mathrm{L}$, d third-group aromatics, (1) $C=0.01 \mathrm{~g} / \mathrm{L}$, (2) $C=0.0012 \mathrm{~g} / \mathrm{L}$, e fourth-group aromatics, (1) $C=0.011 \mathrm{~g} / \mathrm{L}$; (2) $C=0.0011 \mathrm{~g} / \mathrm{L}$

into the higher energy region of the spectrum (up to $251 \mathrm{~nm}$ ) (Fig. 2c). When the components under study are exposed to photo-irradiation for periods of more than 3-7 h, in the spectral region of 190-240 nm, an intense and broad absorption band is recorded $(D=2.5860)$, which indicates the formation of a complex structure. In this case, the optical densities of bi- and tri-cyclic aromatic hydrocarbons decrease, and a new absorption band of about $248 \mathrm{~nm}$ is formed, which is associated with quinone compounds.

Prior to light irradiation on the fourth-group aromatics, absorption bands are observed in the $210-260 \mathrm{~nm}$ and 290-334 nm spectra, which is due to the complexity of their structure (Fig. 2d). Photo-irradiation with UV light source for 1,3 , and $7 \mathrm{~h}$ decreased the $\lambda_{\max }$ of aromatic hydrocarbons. The absorption bands with a lower intensity correspond to benzene $(210 \mathrm{~nm})$, naphthalene $(230 \mathrm{~nm})$, phenanthrene (259 nm), 1,2-benzanthracene and 3,4-benzphenanthrene $(290 \mathrm{~nm})$. In this case, a decrease in the optical intensity of the $\lambda_{\text {max }}$ is observed. As the radiation continues, the absorption band at $259 \mathrm{~nm}$ in accordance with phenanthrene shifts to the high energetic spectral region in the following order: $259 \mathrm{~nm} \rightarrow 254 \mathrm{~nm} \rightarrow 245 \mathrm{~nm} \rightarrow 243 \mathrm{~nm}$ (Fig. $2 d$ ).

During the photooxidation process, quinones are formed by the interaction of an oxygen molecule with three-ring aromatics. It has been found that the inclusion of electro-donor substituents in the polycyclic aromatic molecule causes the hypsochromic displacement of the maximum adsorption band, hence the $\pi \pi^{*}$ transition is replaced by $1-\alpha_{\pi}$ transitions [21]. As can be seen from the spectrum, a hypsochromic shift in the PLs spectra is observed after prolonged exposure to irradiation. The hypsochromic shift of the maximum absorption band $\left(\lambda_{\max }\right)$ of polycyclic aromatics in separated fraction of BO after photo-irradiation at 243, 245, 247, 248, 250 and $251 \mathrm{~nm}$ are associated with the formation of quinones (Fig. $2 \mathrm{a}-\mathrm{d}$ ). Moreover, increasing the intensity of $\lambda_{\max }$ in the phenyl ring indicates the formation of endoperoxides and diphenyls.

Using IR and UV spectroscopies, the plausible mechanisms of conversion processes in polycyclic and other aromatics in $\mathrm{BO}$ were given by exposing to the photo-irradiation at different time intervals.

As known, when oil is exposed to radiation, some processes such as fluorescence, dimerization, and photooxidation can be observed in its aromatic fractions [6]. Fluorescence usually occurs in dilute solutions, while dimerization can occur in high-concentration polycyclic aromatic hydrocarbon solutions. Due to the use of dilute solutions (0.0011-0.02 g/L) in our research, the probability of dimerization in polycyclic aromatics is negligible. It can be concluded that only the fluorescence and photooxidation processes in the $\mathrm{BO}$ can be performed after irradiation under identified conditions. As mentioned before, the photooxidation of oil is happened by two mechanisms: the ion radical and the molecular. The results of studies show that the use of sensibilizator is not required for the photooxidation of polycyclic aromatics in oil samples. The presence of molecular oxygen in these aromatics is sufficient for photochemical processes.

It is known that naphthenic-paraffinic hydrocarbon bonds that have a large ionization potential in the $2-6 \mathrm{eV}$ spectral region under study are not broken [25]. However, during a photochemical process, in the excited BO sample as a result of a two-quantum mechanism, the bond in naphthenic and paraffinic hydrocarbons is broken. Because the energy of the triplet level for these hydrocarbons is greater than the bonding energy of $E_{\mathrm{C}-\mathrm{H}}: E^{*}>E_{\mathrm{C}-\mathrm{H}}(\geq 9 \mathrm{eV})$. This process takes place as follows: When the $\mathrm{BO}$ is irradiated, in the initiation step, the alkyl polycyclic aromatics, which act as photo-sensibilizator, absorb the first optical quantum and change from the free state to the excited singlet state $\left(\mathrm{S}^{*}\right)$, which in this case their life span is very short. In the next step, as a result of the intercombination conversion, they change to triplet state. In the final step, the molecule absorbs the second quantum and becomes a stimulus triplet $\left(\mathrm{T}^{*}\right)$. In this case, the energy of the stimulus polycyclic aromatic molecule is equal to the sum of the energy of two optical quanta, which is less than the energy required to break the $\mathrm{C}-\mathrm{C}$ and $\mathrm{C}-\mathrm{H}$ aromatic hydrocarbon bonds. Therefore, no change in the aromatic ring occurs and this stimulus triplet aromatic transfers its energy to the side chain and breaks the $\mathrm{C}-\mathrm{H}$ bond of the $\mathrm{C}-\mathrm{C}$ chain. The reason is that this energy is sufficient to break the alkyl chain bond, resulting in alkyl radicals $(\mathrm{R} \bullet)$. These radicals are unstable at room temperature and readily react with oxygen to form singlet, doublet, and triplet peroxide radicals. Subsequent processes follow a radical chain mechanism. It has been proposed [29] that the decomposition of peroxides created by singlet and doublet radicals yields alcohol, ketone (aldehyde) and singlet oxygen $\left({ }^{1} \mathrm{O}_{2}\right)$, whilst the decomposition of triplet peroxide radicals produces two alkoxyl and triplet oxygen $\left({ }^{3} \mathrm{O}_{2}\right)$ radicals. Singlet oxygen state is created by the interaction of the $\mathrm{S}^{*}$ and $\mathrm{T}^{*}$ states of aromatics with ${ }^{3} \mathrm{O}_{2}$ and this singlet oxygen interacts with aromatic hydrocarbons to form cyclic peroxides. Oxygenated compounds accumulate in the mixture resulting from the decomposition of these compounds [10].

The following are the proposed reactions of the naphthalene, which is also high in the BO sample, with the chainradical mechanism during irradiation.

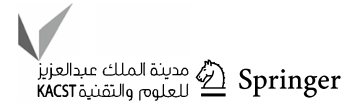


Table $2 \mathrm{BO}$ and the amount of various aromatic hydrocarbons in its separated aromatic groups

\begin{tabular}{|c|c|c|c|c|c|}
\hline \multirow[t]{2}{*}{ Petroleum and its composition } & \multicolumn{5}{|c|}{ Amount of benzene and polycyclic aromatics, (\% weight) } \\
\hline & Benzene (\%) & Naphthalene $(\%)$ & Phenanthrene $(\%)$ & Anthracene $(\%)$ & Total \\
\hline BO sample & $9.2(2.02)^{\mathrm{a}}$ & $5.2(1.64)$ & $1.3(0.62)$ & $0.9(0.07)$ & 16.5 \\
\hline First-group aromatics & $11.3(1.43)$ & $8.3(1.13)$ & $3.5(0.46)$ & - & 23.1 \\
\hline Second-group aromatics & $13.1(2.57)$ & $10.5(1.74)$ & $8.2(0.20)$ & $4.6(0.20)$ & 36.6 \\
\hline Third-group aromatics & $10.4(0.70)$ & $11.9(1.49)$ & $8.1(0.29)$ & $9.3(0.21)$ & 39.7 \\
\hline Fourth-group aromatics & $10.2(1.82)$ & $13.8(1.96)$ & $6.1(1.62)$ & $8.2(0.20)$ & 38.5 \\
\hline Tar & $8.2(2.16)$ & $14.1(1.40)$ & $3.3(0.75)$ & $3.4(0.09)$ & 29.7 \\
\hline
\end{tabular}

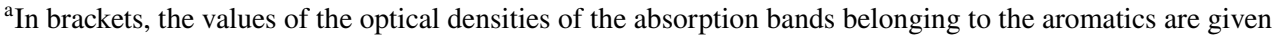

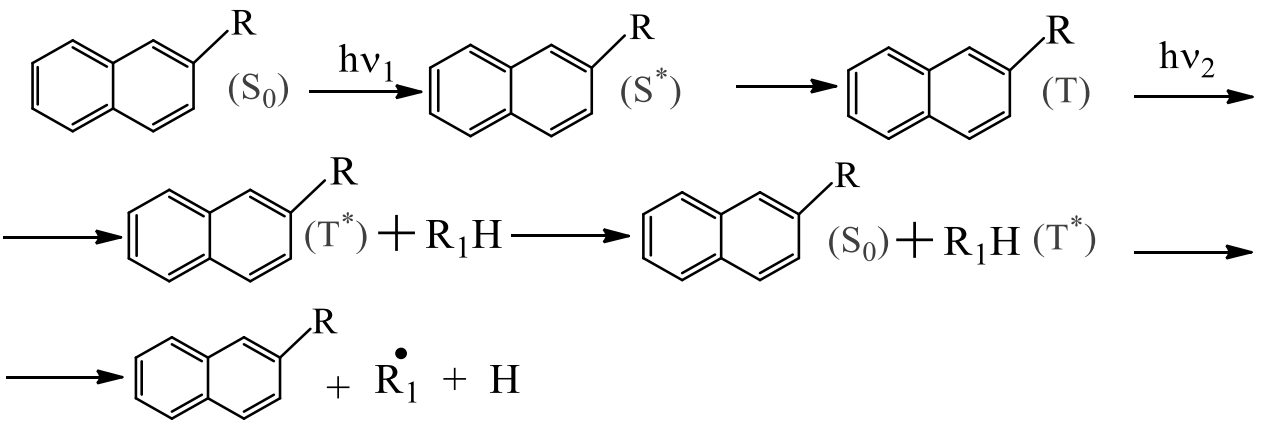

Reactions with mono- and binary peroxide radicals:

$$
\begin{gathered}
\mathrm{R}_{1} \cdot+{ }^{3} \mathrm{O}_{2} \longrightarrow \mathrm{R}_{1} \mathrm{O}_{2}^{\cdot} \\
2 \mathrm{R}_{1} \mathrm{O}_{2} \longrightarrow \mathrm{R}_{1} \mathrm{OOOOR}_{1} \longrightarrow \mathrm{R}-\mathrm{C}=\mathrm{O}\left(\mathrm{R}-\mathrm{C}^{\prime \prime}{ }_{\mathrm{H}}^{\mathrm{O}}\right)+\mathrm{ROH}+{ }^{1} \mathrm{O}_{2}
\end{gathered}
$$

Reactions with ternary peroxide radicals:

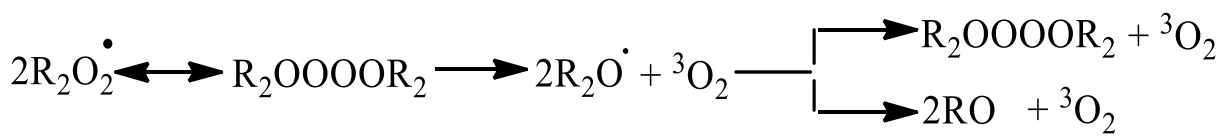

In the above photooxidation reaction sample, naphthalene plays the role of a sensibilizator as a polycyclic aromatic hydrocarbon. However, in this process, other polycyclic aromatic hydrocarbons found in BO sample can also have the same function of sensibilizator and break down naphthenic-paraffinic hydrocarbons. Moreover, since the BO sample does not contain olefin hydrocarbons, practically no attention has been paid to their photo-transformation mechanism. On the other hand, photooxidation occurs under the influence of irradiation as well as on the molecular mechanism. Thus, this process takes place in the inner molecule of polycyclic aromatics and as a result, endoperoxide, quinone and hydroquinone are formed $[11,26]$. The photo-oxides formed by the sample's photo-irradiation in the oxygen medium are decomposed and caused the quanta to be disjointed. However, it should be noted that linear aromatic hydrocarbons are oxidized using a single quantum mechanism in an oxygen environment to form endoperoxides. This 


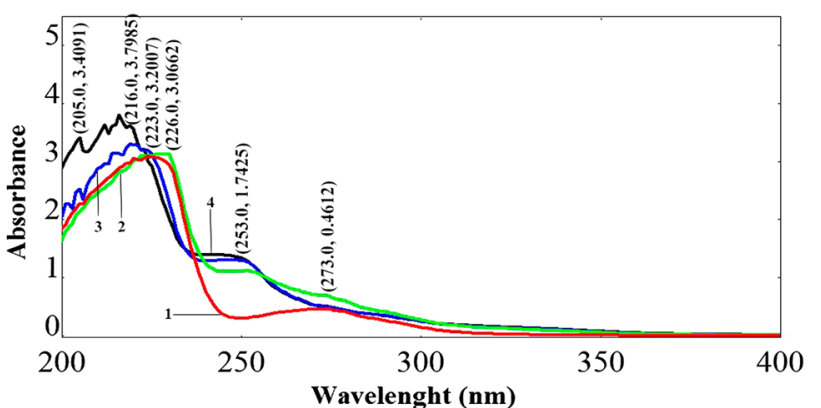

(a)

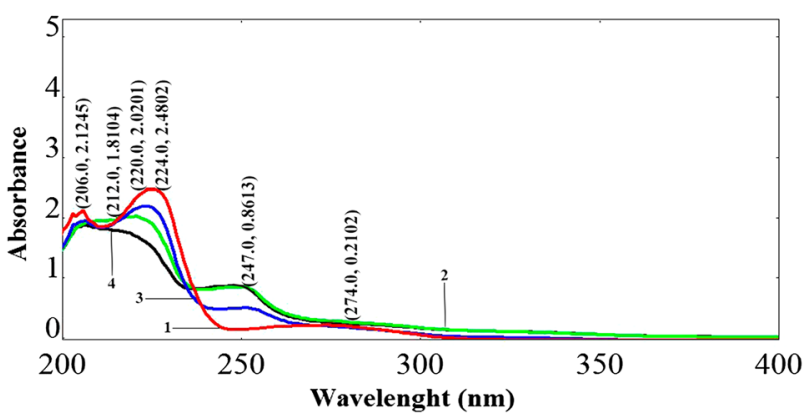

(b)

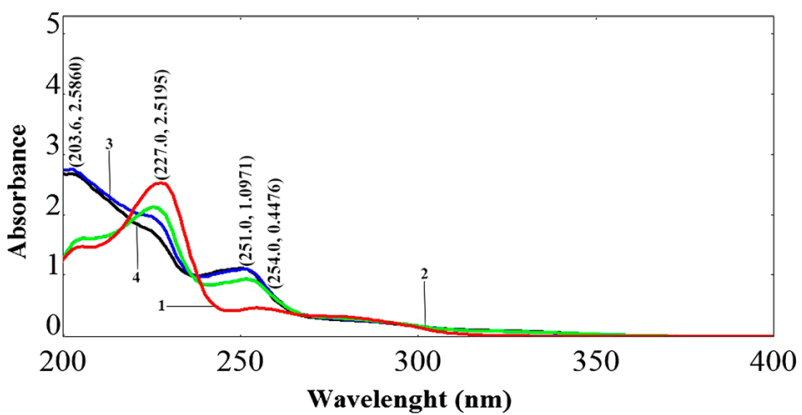

(c)

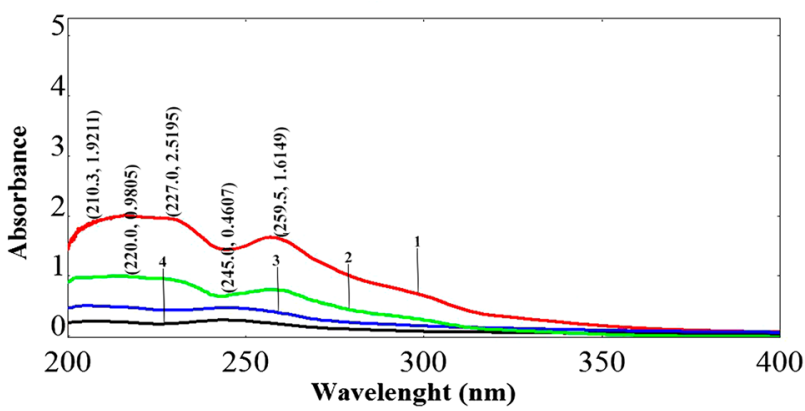

(d)

Fig. 2 UV-absorption spectra of dilute solutions of sample: a firstgroup aromatics: (1) before irradiation, (2) $30 \mathrm{~min}$, (3) $1 \mathrm{~h}$, (4) $3 \mathrm{~h}$. b second-group aromatics: (1) before irradiation, (2) $30 \mathrm{~min}$, (3) $1 \mathrm{~h}$, (4) $3 \mathrm{~h}$. c third-group aromatics: (1) before radiation, (2) $1 \mathrm{~h}$, (3) $3 \mathrm{~h}$, (4) $7 \mathrm{~h}$. d fourth-group aromatics: (1) before radiation, (2) $1 \mathrm{~h}$, (3) $3 \mathrm{~h},(4) 7 \mathrm{~h}$ reaction is reversible and accumulates optical energy in the form of chemical energy. When the system is heated, this energy is released in the form of light. As a result of the continued radiation of endoperoxides formed by photooxidation of linear aromatics, they produce quinone and hydroquinone. This is also observed in the UV spectra with an increase in the intensity of $\lambda_{\max }$ of the phenyl ring and a hypsochromic shift of the absorption bands (Scheme 1).

Unlike anthracene-type aromatic hydrocarbons, phenes (phenanthrene) form cyclic peroxides during photooxidation. In addition, after their decomposition, no illumination is observed, and also this process is irreversible (Scheme 2).

The formation of oxy-compounds after irradiation of aromatics was also confirmed by IR spectroscopy. The IR spectra of the aromatic samples after exposure to photo-radiation at different periods are shown in Fig. 3 . The absorption bands 1657,1712 , and $1770 \mathrm{~cm}^{-1}$ observed in the IR spectra belong to the carbonyl group $(\mathrm{C}=\mathrm{O})$ and confirm that the oxidation processes in the studied oil sample took place after prolonged photo-irradiation. After photooxidation, the sharp increase in the optical density of the $1712 \mathrm{~cm}^{-1}$ absorption band, which is characteristic of the $\mathrm{C}=\mathrm{O}$ group, is due to the oxidation of the alkyl group in the side chain to form aldehydes and ketones. The photooxidation process in the alkyl group is of a chain-radical nature. In contrast, the formation of an absorption band at $1657 \mathrm{~cm}^{-1}$ related to the $\mathrm{C}=\mathrm{O}$ bond of quinone in the IR spectra confirms that the photooxidation reactions in aromatics proceed by a molecular mechanism.

As can be seen from the IR spectra of the separated aromatic groups (except for the first group), after photo-irradiation, absorption bands corresponding to the deformation $\left(1035,1186 \mathrm{~cm}^{-1}\right)$ and valence $\left(3435 \mathrm{~cm}^{-1}\right)$ oscillations of the $\mathrm{OH}$ group are formed. In the second and fourth groups, the intensity of absorption bands belonging to the $\mathrm{OH}$ group is lower than in the third group. This fact indicates that after the photooxidation process, more aldehydes, ketones, and alcohols are formed in the third-group aromatics of BO.

To compare the optical density of the $1730 \mathrm{~cm}^{-1}$ adsorption band related to the carbonyl group, which is characteristic of aldehydes and ketones, different aromatic groups were exposed to photo-irradiation for up to $10 \mathrm{~h}$. Their IR spectra are determined every $2 \mathrm{~h}$ and their change over time is shown in Fig. 4.

As indicated, the oxidation process in the various aromatic groups of BO is initially delayed and this process lasted for 4 and $8 \mathrm{~h}$ in the third and fourth aromatic groups, respectively. Consequently, during the photooxidation process lasting up to $10 \mathrm{~h}$, the optical densities of the $1730 \mathrm{~cm}^{-1}$ absorption band of third and fourth aromatic groups were 


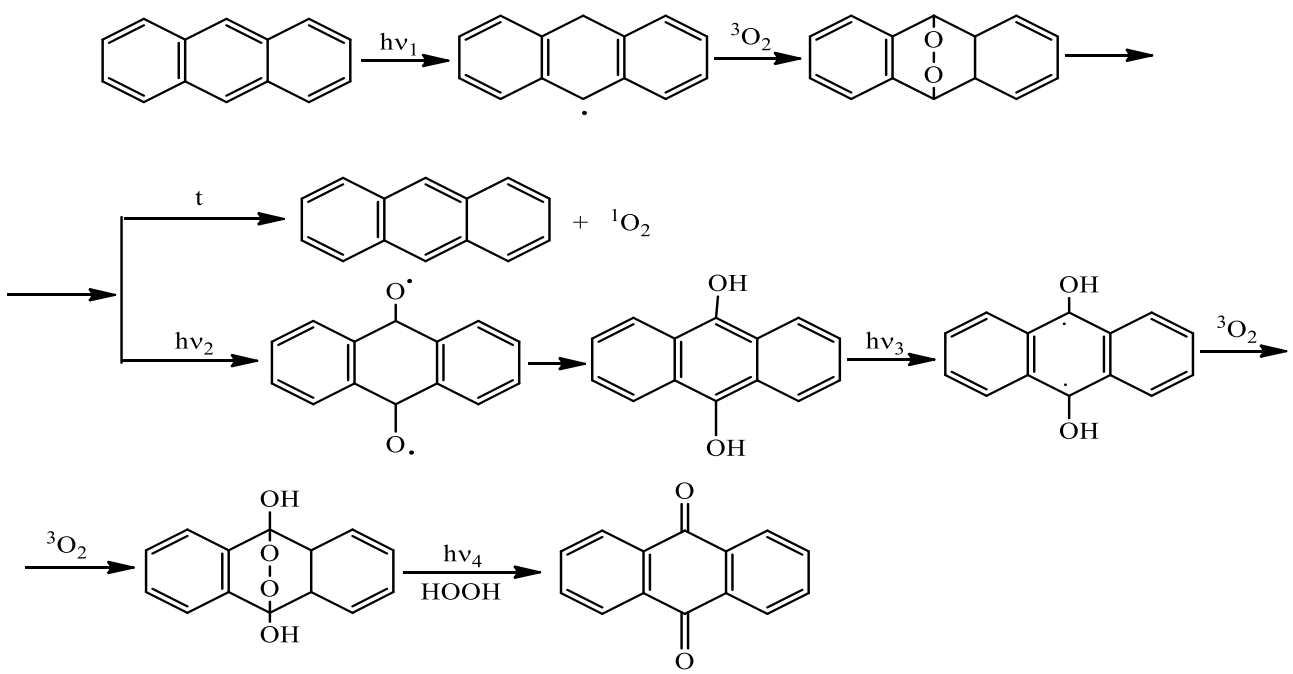

Scheme 1 Photoradiation of linear aromatics (anthracene type) in the oxygen medium

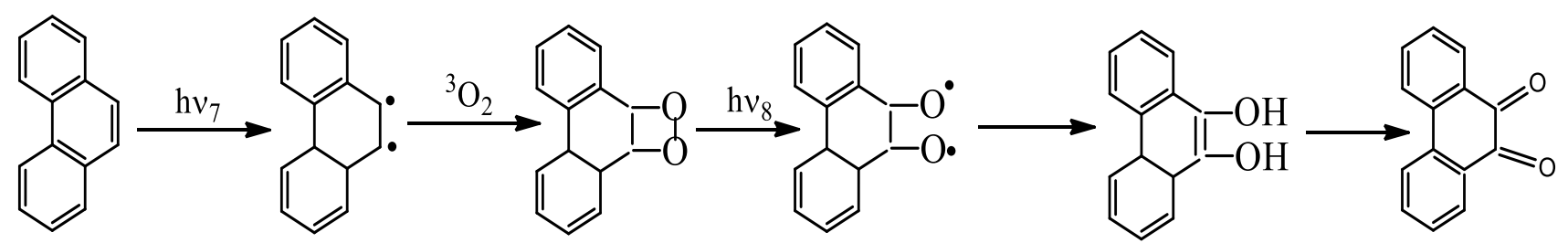

Scheme 2 Photoradiation of phenes-type aromatics in the oxygen medium

$D=0.12$ and $D=0.08$, respectively. This indicates that photooxidation in these aromatic groups is relatively weak over a period of time.

To study the application of the third- and fourth-group aromatics as PLs, which their photooxidation processes are weak, $15 \%$ solutions of them in kerosene was prepared. Then these solutions, under UV light by giving yellow-blue and yellow-green colors, were used to detect defects in polishing cracks. The kerosene or liquid paraffin solution of these PLs is spread as a thin layer on the surface of polished metal. Under the influence of UV light, defects could be observed in several parts of the illuminated areas.

\section{Conclusion}

For Balakhani oil to be used as petroleum luminophores, the various aromatic groups separated by column absorption chromatography were studied by UV and IR spectroscopies by exposure to photo-irradiation at different times. Based on the electron absorption spectra of the samples and the considerations of the photochemical transformation mechanisms of different aromatic groups, it was proposed that the photochemical transformation processes in the aromatics of the studied oil proceeded by radical-chain and molecular mechanisms. It has been found that linear aromatic compounds oxidized in an oxygen environment to form endoperoxides and these compounds form quinones and hydroquinones during subsequent photooxidation, while acenes form cyclic peroxides.

Photophysical and photochemical transformations in PLs derived directly from crude oil (in this study) are much slower than in PLs obtained by catalytic cracking of heavy diesel or pyrolysis of heavy tar, which are oil-refining products.

The results show that the photooxidation process takes relatively long time in all aromatic groups derived from BO. These aromatic groups (especially third and fourth groups) are photostable because of photochemical conversion and slowly converted to quinones. This property increases their luminescence and allows them to be used as PLs.

At the same time, these PLs have variable luminescence properties. The efficiency of these PLs compared to multi-ring aromatic-containing PLs shows that the spectral-luminescent properties of them vary over a wide range (200-720 nm). On the other hand, as the concentration of the solution changes, it luminesces in different colors. 


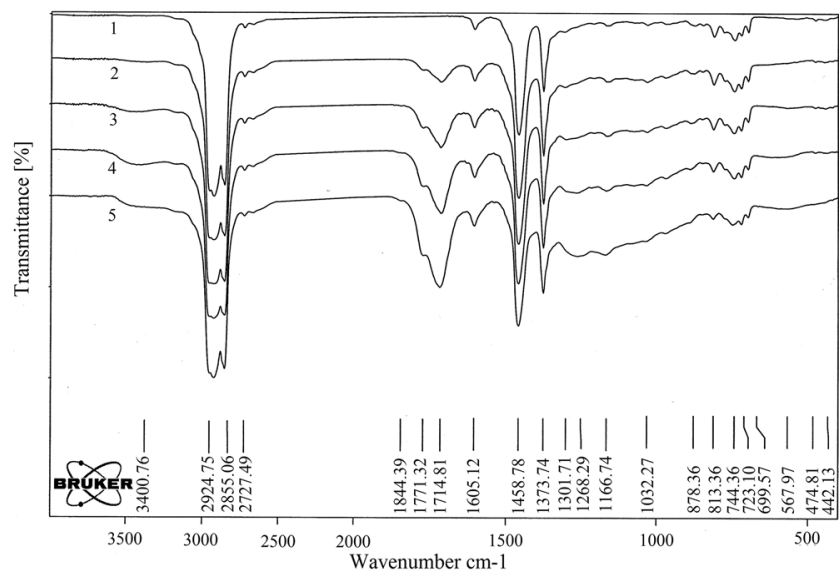

(a)

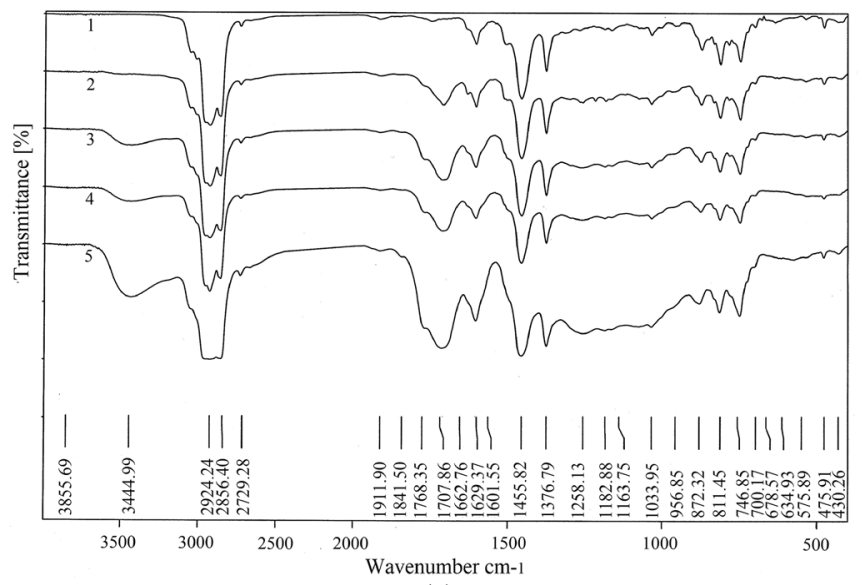

(c)

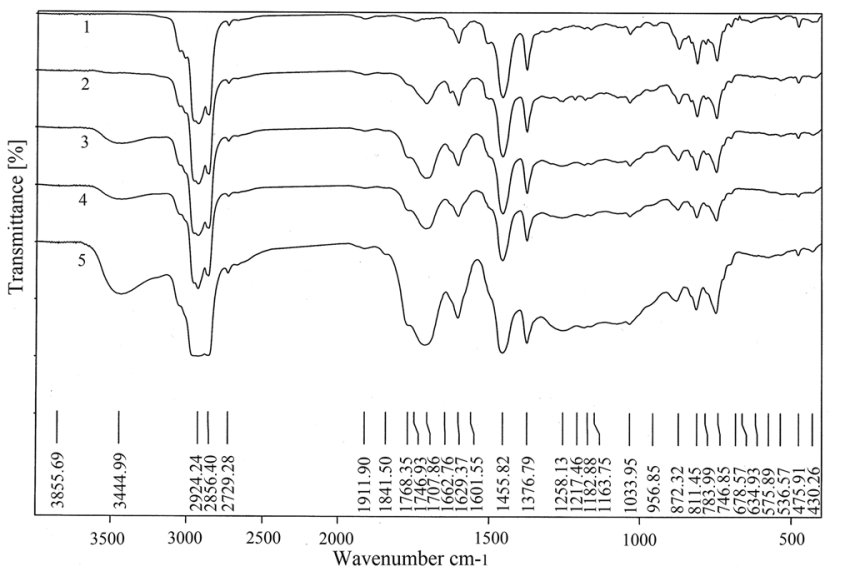

(b)

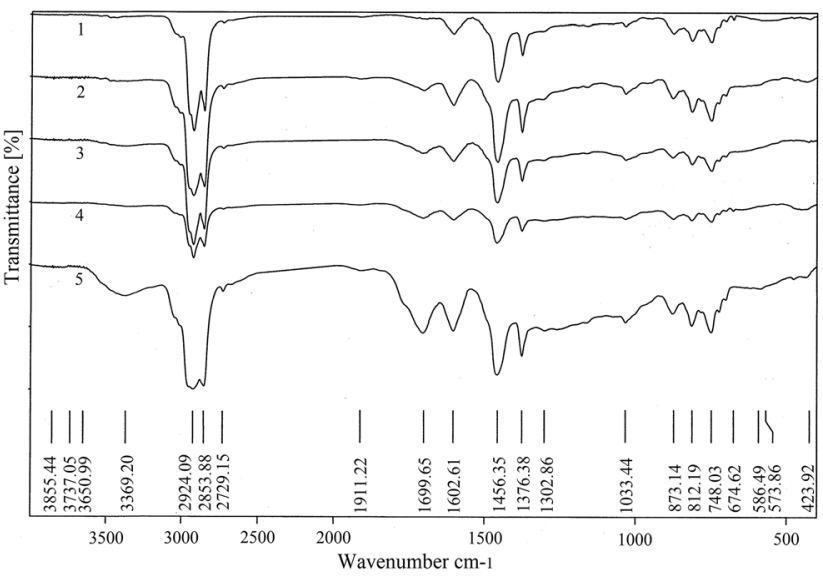

(d)

Fig. 3 IR spectra of BO separated groups after 2, 4, 6, 8, and 10 h of photo-irradiation. (a first group, b second group, $\mathbf{c}$ third, and $\mathbf{d}$ fourthgroup aromatics. 1: $2 \mathrm{~h}, 2: 4 \mathrm{~h}, 3: 6 \mathrm{~h}, 4: 8 \mathrm{~h}$, and 5: $10 \mathrm{~h}$ photo-irradiation

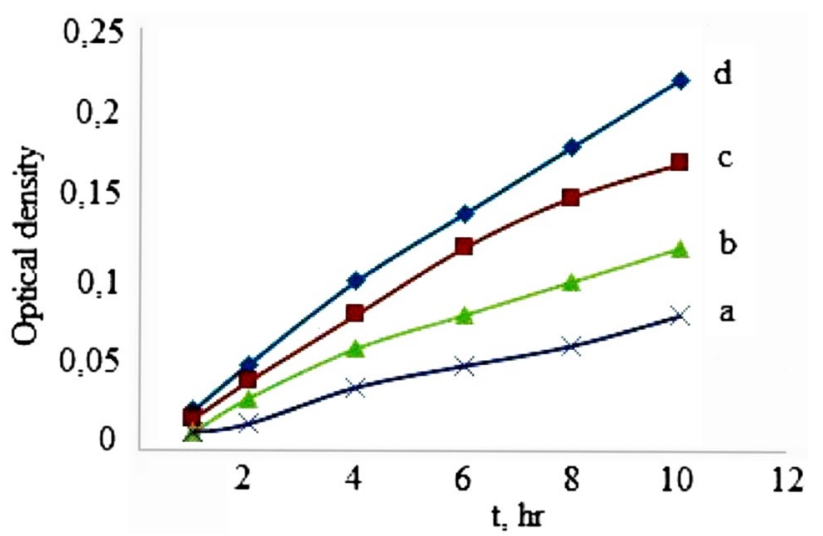

Fig. 4 The optical density of the $1730 \mathrm{~cm}^{-1}$ adsorption band of different aromatic groups (a first group, b second group, $\mathbf{c}$ third, and $\mathbf{d}$ fourth-group aromatics)

Open Access This article is licensed under a Creative Commons Attribution 4.0 International License, which permits use, sharing, adaptation, distribution and reproduction in any medium or format, as long as you give appropriate credit to the original author(s) and the source, provide a link to the Creative Commons licence, and indicate if changes were made. The images or other third party material in this article are included in the article's Creative Commons licence, unless indicated otherwise in a credit line to the material. If material is not included in the article's Creative Commons licence and your intended use is not permitted by statutory regulation or exceeds the permitted use, you will need to obtain permission directly from the copyright holder. To view a copy of this licence, visit http://creativecommons.org/licenses/by/4.0/.

\section{References}

1. Abbasov VM, Mamedov AP, Nadzhafova GA, Musaev NN, Dzhafarova RA, Nadzhafova MA, Salmanova ChK, Akhmedbekova SF, Samedova AS (2013) Photo- and chemiluminescence of therapeutic naphthalan oil and energy transfer between its components. Oil Process Petrochem 8:11-18

2. Abdulkadir I, Uba S, Salihu AA, Almustapha MN (2016) A rapid method of crude oil analysis using FT-IR spectroscopy. Niger J Basic Appl Sci 24(1):47-55. https://doi.org/10.4314/njbas.v24i1 .8 
3. Akhmedbekova SF, Salmanova CK, Zeinalov EB, Mamedov AP, Mamedova FM (2009) Effect of photoirradiation on the antioxidant properties of secondary resins and asphaltenes. Pet Chem 49:235-239. https://doi.org/10.1134/S0965544109030086

4. Al-Lihaibi SS (2003) Photo-oxidation products of petroleum hydrocarbons in the Eastern Red Sea coastal waters. Environ Int. https://doi.org/10.1016/s0160-4120(02)00085-5

5. Bahrudeen SH, Chandra SB, Bharathkumar N, Anil KS (2018) Chromatography as an efficient technique for the separation of diversified nanoparticles. Nanomater Chromatogr. https://doi. org/10.1016/B978-0-12-812792-6.00019-4

6. Chen-Ho T, Li-Zhu W (1996) Enhancement of intramolecular excimer formation, photodimerization and energy transfer of naphthalene end-labelled poly(ethylene glycol) oligomers via complexation of alkali-metal and lanthanide cations. J Chem Soc Faraday Trans 92:1381-1385. https://doi.org/10.1039/FT996 9201381

7. Ganjali ST, Niknafs BN, Khosravi M (2007) Photo-oxidation of crude petroleum maltenic fraction in natural simulated conditions and structural elucidation of photoproducts. Iran J Environ Health Sci Eng 4:37-42

8. Kopsch H (1995) Thermal methods in petroleum analysis. VCH Verlagsgesellschaft $\mathrm{mbH}$, New York. https://doi. org/10.1002/9783527615155.fmatter

9. Hongtao Y (2002) Environmental carcinogenic polycyclic aromatic hydrocarbons: photochemistry and phototoxicity. J Environ Sci Health Part C. https://doi.org/10.1081/GNC-120016203

10. Japharova RA (2004) Akkumulyatsiya i peredacha energii $v$ neftyanykh lyuminoforakh. Neftekhimiya 2:156-160

11. Krichevsky GE (1986) Photochemical transformations of dyes and light stabilization of painted materials. Chemistry, Moscow

12. Krylov VA, Mosyagin PV, Bochkareva LV, Matkivskaya YO (2010) Influence of luminescent lamps light on stability of polycyclic aromatic hydrocarbons samples. Vestnik Lobachevsky State Univ Nizhni Novgorod 4(1):79-85

13. Larson RA, Hunt LL, Blankenship DW (1977) Formation of toxic products from a \#2 fuel oil by photooxidation. Environ Sci Technol 11:492-496. https://doi.org/10.1021/es60128a002

14. Mamedov AP, Jafarova RA, Najafova MA, Salmanova CK (2014) Spectral and luminescent properties, EPR and photochemistry of petroleum products. Elm Publishing House, Baku, p 327

15. Mamedov AP, Rustamov MI, Japharova RA, Salmanova ChK (2000) Photochemical processes and accumulation of solar energy in oil luminophors. Turk J Chem 24(1):35-42

16. Mamedov AP, Salmanova ChQ, Jafarova RA, Najafova MA, Akhmedbekova SF, Yolchuyeva UJ (2016) Influence photoradiation on thermoluminescence hydrocarbons of heavy oil residues. Mir nefteproduktov. Vestnik neftyanykh kompaniy 3:24-29

17. Mustafa VK, Ender O (1994) Thermal analysis of crude oil-lignite mixtures by differential scanning calorimetry. Fuel 73(4):500 504. https://doi.org/10.1016/0016-2361(94)90031-0

18. Nadzhafova MA, Akhmedbekova SF, Tagieva ShF, Dzhafarova RA, Salmanova ChK, Mamedov AP (2013) Photodecomposition of water in zeolites sensitized by polycyclic aromatic oil hydrocarbons. Process Petrochem Oil Refin 54(2):157-164

19. Nadzhafova MA, Mamedov AP (2010) Sensitized decomposition upon photoirradiation of heavy oil residues. Process Petrochem Oil Refin 1(14):61-66

20. Nicodem DE, Fernandes MCZ, Guedes CLB, Correa RJ (1997) Photochemical processes and the environmental impact of petroleum spills. Biogeochemistry 39:121-138

21. Nurmukhametov RN (1971) Poglosheniye i lyuminesentsiya aromaticheskikh soedineniy. Khimiya, Moscow

22. Ok S, Rajasekaran N, Sabti MA, Joseph GA (2020) Spectroscopic analysis of crude oil asphaltenes at molecular level. Pet Chem 60:802-809. https://doi.org/10.1134/s0965544120070117

23. Richard FL (2003) Photo-oxidation and photo-toxicity of crude and refined oils. Spill Sci Technol Bull. https://doi.org/10.1016/ S1353-2561(03)00015-X

24. Ryder AG (2005) Analysis of crude petroleum oils using fluorescence spectroscopy. Rev Fluoresc. https://doi.org/10.1007/0-38723690-2_8

25. Salmanova ChK (2005) Photo okislitelnyye prevrasheniya neftyanogo lyuminophora, polychennogo iz tyazheloy smoli piroliza. Pet Chem 2:151-156

26. Salmanova CK, Dzhafarova RA, Musaev DD, Akhmedbekova SF, Mamedov AP (2009) Thermoluminescence of photoirradiated petroleum luminophores of pyrolytic origin. High Energy Chem 43(5):465-472

27. Siryuk AG, Zimina KI (1962) Primenenie UF spektroskopii dlya analiza shirokikh neftyanykh fraksii. J Appl Spectrosc 2:157

28. Bernard PT, Dietrich HW (1984) Composition of crude oils. In: Petroleum formation and occurrence. Springer, Berlin. https://doi. org/10.1007/978-3-642-87813-8_20

29. Vasilev RF, Tsaplev YuB (2006) Light-created chemiluminescence. Russ Chem Rev. https://doi.org/10.1070/RC2006v075 n11ABEH003631

30. Yolchuyeva UJ, Jafarova RA, Akmedbekova SF, Salmanova ChG, Aliev BM, Namazov AA (2016) Research the chemical composition of Surakhani and Balakhani oil fields by using IR-, NMRspectroscopic methods. J Qafqaz Univ Chem Biol 1:21-26 